\title{
Plasma steroid, relaxin and dihydro-keto-prostaglandin F- $2 \alpha$ changes in the minipig in relation to myometrial electrical and mechanical activity in the pre-partum period
}

\author{
A. D. Watts, A. P. F. Flint $* \S$, G. R. Foxcroft $\uparrow$ and D. G. Porter $\ddagger$ \\ Pre-clinical Veterinary Studies, Department of Anatomy, The Medical School, Bristol BS8 ITD, \\ U.K.; *AFRC Institute of Animal Physiology and Genetics Research, Babraham, \\ Cambridge CB2 4AT, U.K. and $\dagger$ Department of Animal Physiology, University of Nottingham, \\ Sutton Bonington, Leics LE12 5RD, U.K.
}

\begin{abstract}
Summary. Recordings of electromyographic and mechanical activities of the uterus of intact and ovariectomized minipigs during the last days of pregnancy, combined with a frequent blood sampling regimen, indicated that the evolution of electrical activity was dependent upon the clearance both of progesterone and relaxin from the plasma. Increases in dihydro-keto-prostaglandin-F-2 $\alpha$ (DHKF-2 $\alpha$ ) occurred only after the initial decline in progesterone, and were positively correlated with increases in electrical activity only after circulating relaxin titres had fallen. These results demonstrate that relaxin provides for the inhibition of the myometrium during the period when progesterone titres decline. The temporal relationship of the decline of progesterone and the rise in DHKF-2 $\alpha$ suggests that uterine PGF- $2 \alpha$ may not initiate luteolysis in the sow at term.
\end{abstract}

Keywords: relaxin; myometrium; parturition; prostaglandins; pig

\section{Introduction}

Parturition in the pig is presaged by a complex pattern of hormonal changes which have been documented by a number of workers (see Taverne, 1982, for review). Although they have been less intensively studied, the changes in myometrial activity which culminate in labour in the sow have also been described (Zerobin \& Sporri, 1972; Taverne et al., 1979a, b). During most of the last 3 weeks of gestation, when circulating concentrations of progesterone are relatively high, myoelectric activity in the uterus is minimal and restricted to episodes of several minutes duration, principally in areas of muscle overlying the fetuses. However, during the last $4-9 \mathrm{~h}$ of pregnancy the pattern of myometrial activity changes so that regular, synchronized phases of electrical discharge develop and are propagated along the uterine horn (Taverne, 1982). These periods of electrical activity gradually become more frequent and of greater magnitude and eventually culminate in labour contractions.

Unfortunately, the manner in which the myometrium is affected by hormonal changes is not clear from the studies cited above since these have not combined endocrine and myometrial observations in the same animal. Also, the hormones themselves often have been studied separately or by sampling with a frequency which is not rapid enough to delineate precisely their relationship one to another or to changes in myometrial activity.

$\ddagger$ Present address: Department of Biomedical Sciences, Ontario Veterinary College, University of Guelph, Guelph, Ontario, Canada NIG 2W1.

\$Present address: Institute of Zoology, Zoological Society of London, Regent's Park, London NW1 4RY, U.K. 
We have attempted to clarify the pre-partum events by using an intensive blood sampling regimen to study several hormonal substances simultaneously in minipigs from which we monitored electromyographic activity (EMG), and intrauterine pressure (IUP) from the uterus.

\section{Materials and Methods}

\section{Animals and methods}

Animals. Eighteen pregnant miniature gilts weighing $32-58 \mathrm{~kg}$ at the time of surgery were obtained from the herd at the Royal Veterinary College, London. After transportation to Bristol at about 90 days of gestation, followed by acclimatization, the gilts were housed individually under natural lighting and were supplied with water ad libitum. They were fed twice daily with sow nuts (Dalgety Agricultural Ltd, Bristol).

Recording electrodes. Electrodes to record uterine electrical activity were prepared from 3 pairs of 25 -strand Teflon-coated stainless-steel wires (Cooner Corporation, Chatsworth, CA, U.S.A.). The wires were 90,80 and $70 \mathrm{~cm}$ respectively in length and were ensheathed in Silastic tubing (Dow Corning, Reading, Berks, U.K.). They were crimped into hypodermic needle (21-gauge) shafts to enable insertion of the wires into the myometrium. A short section of the wire protruding from the Silastic tubing was stripped of Teflon to ensure electrical contact with the tissues.

Surgery. All gilts were prepared for surgery between 94 and 106 days of gestation as follows. Food was withheld for $24 \mathrm{~h}$ and the animals were pre-medicated with ketamine $(10 \mathrm{mg} / \mathrm{kg}$ i.m.; Vetalar, Parke Davies Co., Pontypool, Gwent, U.K.) and atropine $(0.05 \mathrm{mg} / \mathrm{kg} \mathrm{i.m.).} \mathrm{Once} \mathrm{the} \mathrm{gilts} \mathrm{had} \mathrm{become} \mathrm{somnolent} \mathrm{anaesthesia} \mathrm{was} \mathrm{induced} \mathrm{with} \mathrm{a}$ halothane (I.C.I. Ltd, Macclesfield, Cheshire, U.K.)/nitrous oxide/oxygen mixture administered initially by mask, and subsequently through an endotracheal tube after intubation. Using a strict aseptic technique all animals were fitted with a Silastic catheter (i.d. $2.64 \mathrm{~mm}$, o.d. $4.88 \mathrm{~mm}$ : Dow Corning, Midland, MI, U.S.A.) which was inserted $7-8 \mathrm{~cm}$ into a branch of the external jugular vein through an incision in the ventral wall of the neck. The other end of the catheter was passed subcutaneously to a point behind the left shoulder and brought to the exterior through a small incision in the skin. Throughout the remainder of surgery the gilts were given $5 \%$ dextrose solution in normal saline $(0.9 \%(\mathrm{w} / \mathrm{v}) \mathrm{NaCl})$ via the jugular catheter. Access to the uterus was gained by a mid-line laparotomy incision through which one uterine horn was brought to the exterior at a time. A note was made of the number of fetuses. Electrodes were inserted into the myometrium of the left horn; the first pair were sutured approximately $7 \mathrm{~cm}$ from the bifurcation of the uterus and the remaining two pairs at $10 \mathrm{~cm}$ intervals along the uterine horn towards the ovaries.

An intrauterine balloon (latex; $15 \mathrm{ml}$ capacity undistended) attached to a catheter (PP100, i.d. $0.85 \mathrm{~mm}$; o.d. $1.52 \mathrm{~mm}$ : Portex, Hythe, Kent, U.K.) was inserted between the allantochorion and the endometrium in the left horn through a small incision about $5 \mathrm{~cm}$ from the uterine bifurcation. In 3 of the gilts (from Group 3, see below) a Silastic catheter (i.d. $1.02 \mathrm{~cm}$, o.d. $2.16 \mathrm{~cm}$ : Dow Corning) also was inserted into a branch of the uterine artery. In all animals ovariectomy, or sham ovariectomy in which the ovaries were merely exposed and manipulated, was performed depending upon the group to which the gilt was assigned (see below).

The uterus was returned to the peritoneal cavity, the electrode and balloon catheters were brought through the abdominal incision and the peritoneum and body wall closed around them. The remainder of the catheter was passed subcutaneously from the abdominal incision and brought to the exterior through a small stab incision in the left flank. The electrodes were then attached to a 9-way D connector plug (R. S. Components Ltd, Birmingham, U.K.) to enable recordings to be made on a Grass $7 b$ Polygraph (Grass Instruments, Quincy, MA, U.S.A.).

Immediately after surgery and at $24 \mathrm{~h}$ thereafter each gilt received $2 \mathrm{mg}$ pethidine $/ \mathrm{kg}$ (Arnolds Veterinary Products Ltd, Reading, Berks, U.K.) i.m. for post-operative analgesia. All animals also received $250 \mathrm{mg}$ Penbritin injection (Beechams Research Laboratories, Brentford, Middlesex, U.K.) i.v. daily for 5 days. Each gilt was fitted with a custom-made canvas 'waistcoat' which protected the electrode cables and balloon catheter and housed them in small pockets, thereby facilitating access to them with minimal disturbance to the gilts.

\section{Treatments}

Electromyographic (EMG) and intra-uterine pressure (IUP) recording. Electrical activity of the myometrium and IUP was monitored for at least $2 \mathrm{~h}$ daily for $2-4$ days after surgery until Day $110-112$ of pregnancy when the gilts were moved from their individual pens to a farrowing crate; thereafter EMG was monitored continuously. Each gilt was also observed continuously in the farrowing crate until delivery or euthanasia.

Blood sampling. All blood samples were taken from the jugular catheter and the volume withdrawn was adjusted according to the frequency of sampling (see below). All samples were collected into heparinized (Pularin, Evans Medical Ltd, Liverpool, U.K.) syringes and centrifuged for $10 \mathrm{~min}$ at $2000 \mathrm{~g}$ in a refrigerated centrifuge (Beckman Model TJ6 Beckman Instruments, High Wycombe, Bucks, U.K.); the plasma was stored at $-20^{\circ} \mathrm{C}$ until assayed. The patency of the jugular catheter was ensured by daily flushing and by filling with heparinized ( $250 \mathrm{units} / \mathrm{ml})$ sterile saline when not in use. Daily samples of $5 \mathrm{ml}$ were taken from the time that EMG recordings were begun until the gilts were placed in farrowing crates. Thereafter sampling frequency was determined by the protocols below. 
In Group $1(\mathrm{~N}=4$ : control, sham ovariectomy), blood sampling frequency was increased after the gilts were placed in crates to once every $6 \mathrm{~h}(2 \mathrm{ml})$ until $48 \mathrm{~h}$ before the expected farrowing time, after which $1-\mathrm{ml}$ samples were taken hourly. In Group $2(\mathrm{~N}=6$ : ovariectomy and progesterone treatment), the gilts received progesterone replacement injections (i.m.) immediately before, and after surgery until Day 112 of pregnancy. The dose, which was adjusted in accordance with the recorded level of EMG as assessed by eye, was split and administered in two injections $12 \mathrm{~h}$ apart. It varied from 0.5 to $2 \mathrm{mg} / \mathrm{kg} /$ day and was administered dissolved in arachis oil at a concentration of $20 \mathrm{mg} / \mathrm{ml}$.

In Group $3(\mathrm{~N}=3$ : ovariectomy with progesterone and relaxin treatment), the gilts received progesterone injections (i.m.) of $0.5-2.0 \mathrm{mg} / \mathrm{kg} /$ day as in Group 2. Each gilt also received in addition purified pig relaxin prepared as described in Porter et al. (1981) according to the following schedules: (i) intra-arterial infusion $(\mathrm{N}=2)$-relaxin dissolved in sterile saline $(66 \mu \mathrm{g} / \mathrm{ml})$ was infused into the uterine artery in 2 gilts at the rate $143 \mu \mathrm{g} / \mathrm{h}$ starting about $6.5 \mathrm{~h}$ before the final progesterone injection and continued for a total of more than $55 \mathrm{~h}$; (ii) intramuscular injections -1 gilt received relaxin i.m. every $6 \mathrm{~h}$ beginning $14 \mathrm{~h}$ after the final progesterone injection. The dosage was adjusted in an attempt to mimic the normal endogenous pre-partum rise and was $280 \mu \mathrm{g}$ for Injections $1-4,420 \mu \mathrm{g}$ for Injections 5-7 and $560 \mu \mathrm{g}$ for Injection 8.

\section{Quantitation of EMG activity}

To discriminate between myometrial and other electrical activity, an EMG 'burst' was defined as a series of fluctuations of electrical potential which had an amplitude in excess of $50 \mu \mathrm{V}$, a duration of longer than $5 \mathrm{sec}$ and was separated from any subsequent series by an interval of electrical quiescence of at least $10 \mathrm{sec}$.

The electrical signals were analysed using an Apple II microcomputer (Apple Computer U.K. L.td, Hemel Hempstead, Herts, U.K.) which employed an analog to digital converter card and a specially designed program. This sampled each EMG input every $100 \mathrm{msec}$ and stored the data in a 256 byte circular buffer. The samples were processed as follows using $1 \mathrm{~h}$ time bins as a basis for calculations. The total duration of electrical activity recorded from each electrode in each gilt was calculated and the mean for each animal per hour was expressed as the total amount of time that the uterus was electrically active, expressed in $\mathrm{sec} / \mathrm{h}$. The mean maximum amplitude of the electrical bursts for each hour was expressed in $\mu \mathrm{V}$. The mean frequency of electrical bursts in each animal per hour per electrode was expressed in bursts/h. The mean duration of each electrical burst during each hour time bin was expressed in sec.

\section{Quantitation of IUP recordings}

An IUP cycle was defined as a pressure rise of $>20 \mathrm{mmHg}$ in amplitude followed by a decrease of at least $20 \mathrm{mmHg}$ with the whole event having a duration of $>10 \mathrm{sec}$. Only IUP cycles meeting these criteria were included in the analysis which thereby excluded the majority of pressure changes attributable to non-uterine causes such as tenesmus.

The recordings were analysed in 10 min intervals for (i) frequency of cycles; and (ii) mean amplitude of cycles in $\mathrm{mmHg}$.

\section{Hormone assays}

Progesterone. Progesterone was measured in plasma samples using a radioimmunoassay (Wathes \& Porter, 1982) based on that described by Haresign et al. (1975). The sensitivity of the assay was $20 \cdot 8 \pm 6 \cdot 5 \mathrm{pg} / \mathrm{tube}$ and the inter- and intra-assay coefficients of variation were $21.8 \%$ and $12.6 \%$ respectively.

Relaxin. The details of the pig relaxin assay have been published elsewhere (Taverne et al., 1982). The antiserum cross-reacted $100 \%$ with $\mathrm{Cma}^{-}$relaxin (18-28AAE-Cma ${ }^{-}$kindly donated by Dr B. G. Steinetz), $20 \%$ with N1H relaxin standard, lot D147 (bioassayed at 442 guinea-pig units $/ \mathrm{mg}$ ), $<0.02 \%$ with pig prolactin and $<0.01 \%$ with pig insulin (Sigma Chemical Co., Poole, Dorset, U.K.). Sensitivity of the assay was between 20 and $60 \mathrm{pg} / \mathrm{tube}$ and inter- and intra-assay variation was $17.6 \%$ and $4 \%$ respectively.

Oestradiol-17\%. Oestradiol-17ß was assayed using the radioimmunoassay method of Foxcroft et al. (1984). The sensitivity of the assay was $5.5 \mathrm{pg} /$ tube and the inter- and intra-assay variation was $9.6 \%$ and $6.6 \%$ respectively.

13,14-Dihydro-15-keto-prostaglandin F-2a (DHKF-2a). DHKF-2 $\alpha$ was measured by radioimmunoassay using the method described by Mitchell et al. (1975) after extracting acidified plasma with diethyl ether. Extraction recoveries determined by addition of $\left[{ }^{3} \mathrm{H}\right] \mathrm{DHKF}-2 \alpha$ to plasma before extraction were $76 \cdot 9 \pm 4 \cdot 2 \%$; assay sensitivity was equivalent to $63 \mathrm{pg} / \mathrm{ml}$ plasma and intra- and inter-assay coefficients of variation were 7.8 and $11.2 \%$ respectively. Values were corrected for losses during extraction, and all samples were assayed in duplicate.

\section{Statistical analysis}

To simplify analysis the $30 \mathrm{~h}$ period before delivery in the control group was divided into $6 \times 5 \mathrm{~h}$ periods and in each period the data for the 5 individual 1-h time bins was pooled. All variances are expressed \pm s.e.m.

Differences between mean values obtained for each measure in different time intervals were tested for significance using a one-way analysis of variance or by a two-way analysis using a regression method for non-uniform group sizes. 
These analyses were performed on a Genstat-statistical analysis system (National Algorithms Group Ltd, Banbury, Oxford, U.K.). Correlations among the variables measured were calculated using the Spearman Rank correlation coefficient $\left(r_{\mathrm{s}}\right)$. This was obtained using either the critical value of $r_{\mathrm{s}}$ in cases when $n=10$ or by calculating the ' $t$ ' value using the formula: $t=\sqrt{\mathrm{n}-2 / 1-\left(r_{\mathrm{s}}\right)^{2}}$ (Seigel, 1956). Correlations were sought among mean total duration of electrical activity, DHKF-2 $\alpha$, relaxin, progesterone, oestradiol-17 $\beta$, and the ratio of oestradiol-17 $\beta$ and progesterone titres.

\section{Results}

Group 1: control gilts

Behaviour and gestational data. The 4 gilts in this group maintained their pregnancies uneventfully after surgery and delivered their litters. Behaviour of the gilts in the farrowing crates was normal and blood sampling caused no apparent disturbance. The gilts delivered 4, 3, 5 and 5 live-, and 1,0,0 and 2, still-born piglets respectively. Mean gestation length was $112.6 \pm 0.7$ days with a range of 111 to 114 days. The mean weight of piglets born alive was $479 \pm 23 \mathrm{~g}$ and of still-born piglets $247 \pm 34 \mathrm{~g}$. The duration of parturition was $181 \pm 84 \mathrm{~min}$.

Uterine EMG. Successful recording of EMG activity was obtained from all 12 electrodes implanted in the 4 gilts until some $50 \mathrm{~h}$ before birth, after which one electrode in each of 2 gilts ceased to transmit potentials.

During late gestation EMG activity recorded from the 4 gilts was quite variable, since in 1 gilt infrequent bursts of activity of $1-200 \mu \mathrm{V}$ amplitude and of $30-45 \mathrm{sec}$ duration occurred asynchronously at all 3 electrodes, whereas in another animal synchronized bursts of up to $300 \mu \mathrm{V}$ amplitude and 2 min duration occurred at all 3 electrodes.

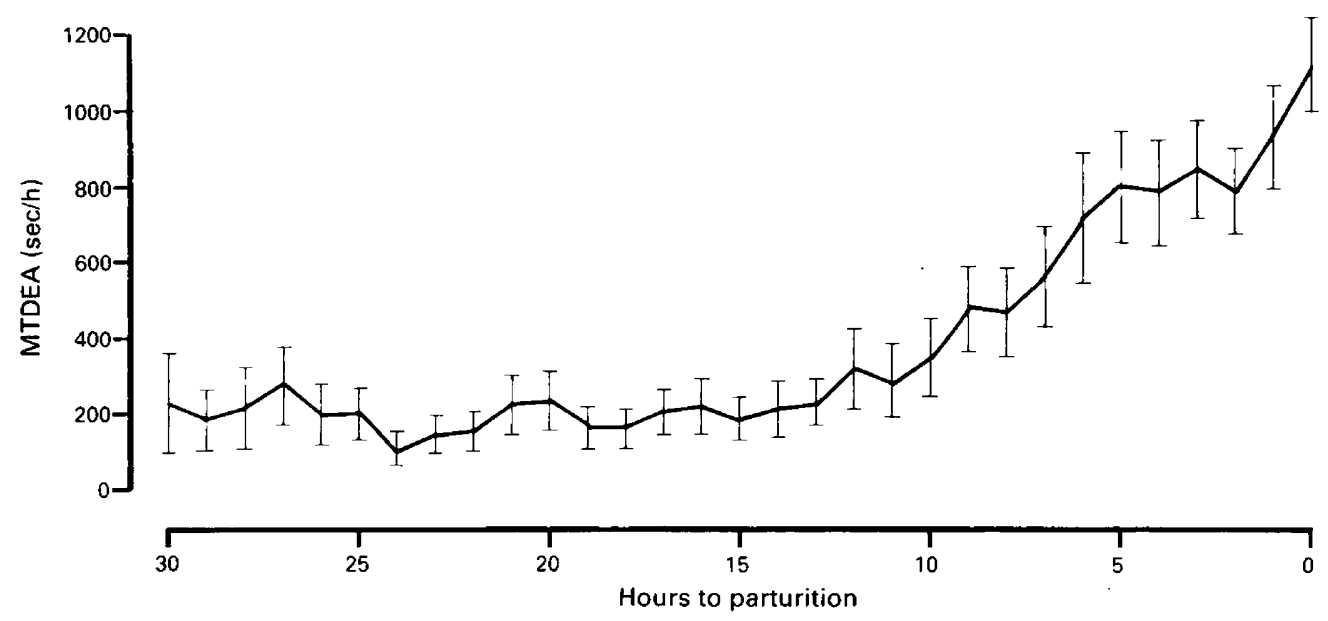

Fig. 1. Mean total duration of electrical activity (MTDEA) in Group 1 (control) pigs for the 30 -h period leading up to parturition. Values are mean \pm s.e.m. for 4 gilts from a total of 7 electrodes, from -30 to $-24 \mathrm{~h}$ and from 10 electrodes for the period $-24 \mathrm{~h}$ to parturition.

However, during the last $30 \mathrm{~h}$ of pregnancy the pattern of EMG activity was similar among all 4 gilts. The mean total duration of electrical activity was relatively stable at between 100 and $400 \mathrm{sec} / \mathrm{h}$ until between 6 and $13 \mathrm{~h}$ before delivery, when it increased steadily up to values greater than $1000 \mathrm{sec} / \mathrm{h}$ at parturition (Fig. 1). Mean burst duration, mean frequency of bursts and mean maximum amplitude showed a comparable tendency to increase gradually as time progressed so that by delivery all measures were significantly elevated $(P<0.01)$ over their values at $-30 \mathrm{~h}$ but 


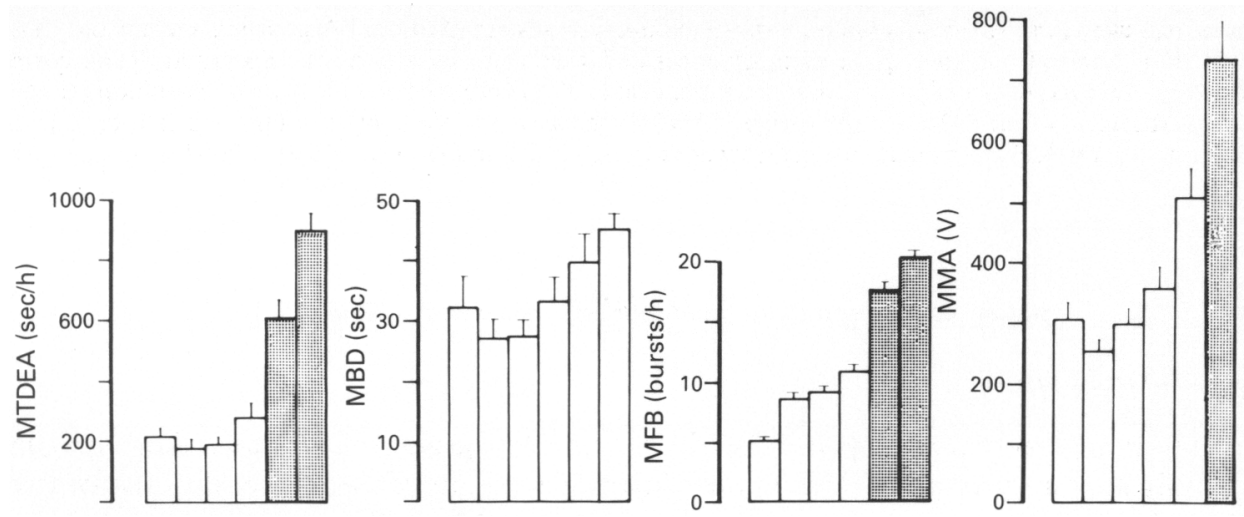

Fig. 2. Mean \pm s.e.m. values for mean total duration of electrical activity (MTDEA), mean burst duration (MBD), mean frequency of bursts (MFB) and mean maximum amplitude (MMA) for pigs in Group 1 (control) for the $6 \times 5 \mathrm{~h}$ intervals during the $30 \mathrm{~h}$ before birth. A difference in shading between two adjacent columns indicates a significant $(P<0.05)$ difference between them.

there were no significant differences between values for the last two 5-h periods except for mean maximum amplitude for which there was a significant increase $(P<0.05$; Fig. 2$)$. However, because of possible changes in impedence in implanted electrodes, the mean maximum amplitude data should be interpreted cautiously.

The most dramatic change occurred in mean total duration of electrical activity between the last but two, and the penultimate, 5 -h period before delivery when total activity changed from $\sim 270$ to $\sim 650 \mathrm{sec} / \mathrm{h}(P<0 \cdot 05)$. Although the increase which occurred between the last two 5 -h time periods before delivery was not statistically significant it raised the mean total duration of electrical activity at the time of expulsion of the piglets to $1125 \pm 124 \mathrm{sec} / \mathrm{h}$ (Fig. 1).

Intrauterine pressure activity. Rises of $>10 \mathrm{mmHg}$ pressure were observed occasionally during late pregnancy in control gilts, but the uterus was mechanically quiescent for the majority of recordings until within a few hours of birth (Fig. 3). Significant increases in both frequency and amplitude of IUP cycles were usually observed within $1-2 \mathrm{~h}$ of the increase in EMG activity, and once activity had begun both frequency and amplitude of IUP cycles increased up to parturition.

At birth IUP cycles had an amplitude up to $90 \mathrm{mmHg}$ upon which were superimposed fast, high amplitude, pressure cycles due to maternal straining. These 'abdominal' pressure cycles were usually synchronized with the peaks of the IUP cycles.

$D H K F-2 a$. By $2-5$ days after operation, plasma DHKF-2 $\alpha$ titres were below $1 \mathrm{ng} / \mathrm{ml}$ and, apart from one or two transient increases, remained at this level until about $20 \mathrm{~h}$ before birth. At this time all gilts exhibited a dramatic increase in plasma DHKF- $2 \alpha$ titres (Fig. 4) although their individual plasma profiles varied from steady to sharply 'saw-toothed' rises. At delivery the plasma titres for the individual gilts in the group ranged from 3.8 to $9.6 \mathrm{ng} / \mathrm{ml}$.

Relaxin. During the period from 12 to 4 days before delivery the plasma titres for 3 of the gilts were similar at an average of $10.4 \pm 1.6 \mathrm{ng} / \mathrm{ml}$, but in the 4 th animal plasma titres were generally 3-6 times greater. In all gilts there was a significant surge in plasma relaxin concentrations some 15-12 $\mathrm{h}$ pre partum, reaching maximum between 55 and $329 \mathrm{ng} / \mathrm{ml}$ (Fig. 4). In all gilts the titres fell sharply after the peak and were between 1.8 and $13.0 \mathrm{ng} / \mathrm{ml}$ at delivery, a statistically significant decrease $(P<0.05)$ occurring from the penultimate to the last 5 -h time period before parturition.

Progesterone. Mean plasma progesterone titre during the period -13 days to $30 \mathrm{~h}$ pre partum for the 4 gilts was $16 \cdot 1 \pm 1 \cdot 0 \mathrm{ng} / \mathrm{ml}$ (range $7 \cdot 9-34.6 \mathrm{ng} / \mathrm{ml}$ ). During the last $30 \mathrm{~h}$ of pregnancy a 

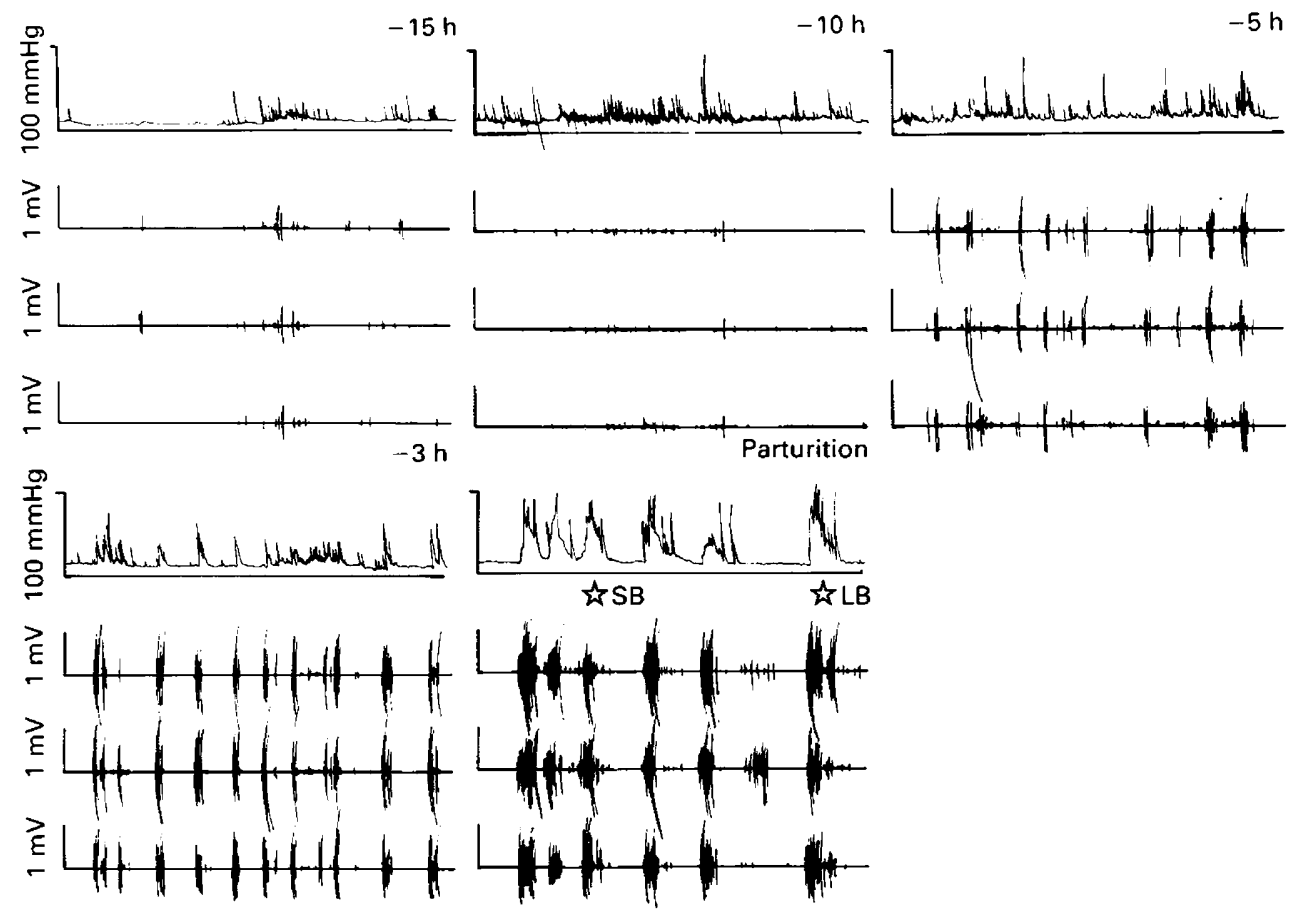

Fig. 3. The evolution of IUP and EMG activity in a control gilt from Group 1 during the last $15 \mathrm{~h}$ of pregnancy. Each time period illustrates $20 \mathrm{~min}$ of recording. $\mathrm{SB}=$ stillbirths; $\mathrm{LB}=$ livebirths.

significant decrease in progesterone titre occurred in all gilts so that at delivery the mean titre was $4.31 \pm 0.69 \mathrm{ng} / \mathrm{ml}$ (Fig. 4).

Oestradiol-17 $\beta$. Plasma titres of oestradiol-17 $\beta$ varied within and among the gilts over a relatively wide range $(48-333 \mathrm{pg} / \mathrm{ml})$ but in all 4 animals an increase was observed during the last $30 \mathrm{~h}$ from a mean of $152 \pm 18 \mathrm{pg} / \mathrm{ml}$ to $282 \pm 64 \mathrm{pg} / \mathrm{ml}$ during the last $4 \mathrm{~h}$ before parturition $(P<0.05)$ (Fig. 4).

Correlations. Over the last $30 \mathrm{~h}$ of gestation there was a significant positive correlation in 3 out of 4 gilts $(P<0.025)$ between mean total duration of electrical activity levels and plasma DHKF-2 $\alpha$ titres, and likewise in 3 out of 4 gilts $(P<0.05)$ between mean total duration of electrical activity and oestradiol-17 $\beta$ titres (Table 1). A significant negative correlation $(P<0 \cdot 01)$, however, was demonstrable between plasma relaxin titre and mean total duration of electrical activity. There was no significant correlation between progesterone titres and any other variable analysed although both mean total duration of electrical activity ( 3 out of 4 gilts) and DHKF- $2 \alpha$ titres (all gilts) were positively correlated $(P<0.05)$ with the plasma oestradiol-17 $\beta$ to progesterone ratio.

\section{Group 2: ovariectomized and progesterone-treated gilts}

Behaviour and gestational data. Until about $30-40 \mathrm{~h}$ after the final injection of progesterone on Day 112 these 6 gilts showed no difference in behaviour from controls. During the last $30-40 \mathrm{~h}$ 3 gilts exhibited normal nesting behaviour but 3 did not. All gilts adopted a recumbent position for labour but the extent of maternal straining movements was noticeably less than in the controls. None of the gilts in this group gave birth to their litters unaided, and so at the time of intervention 


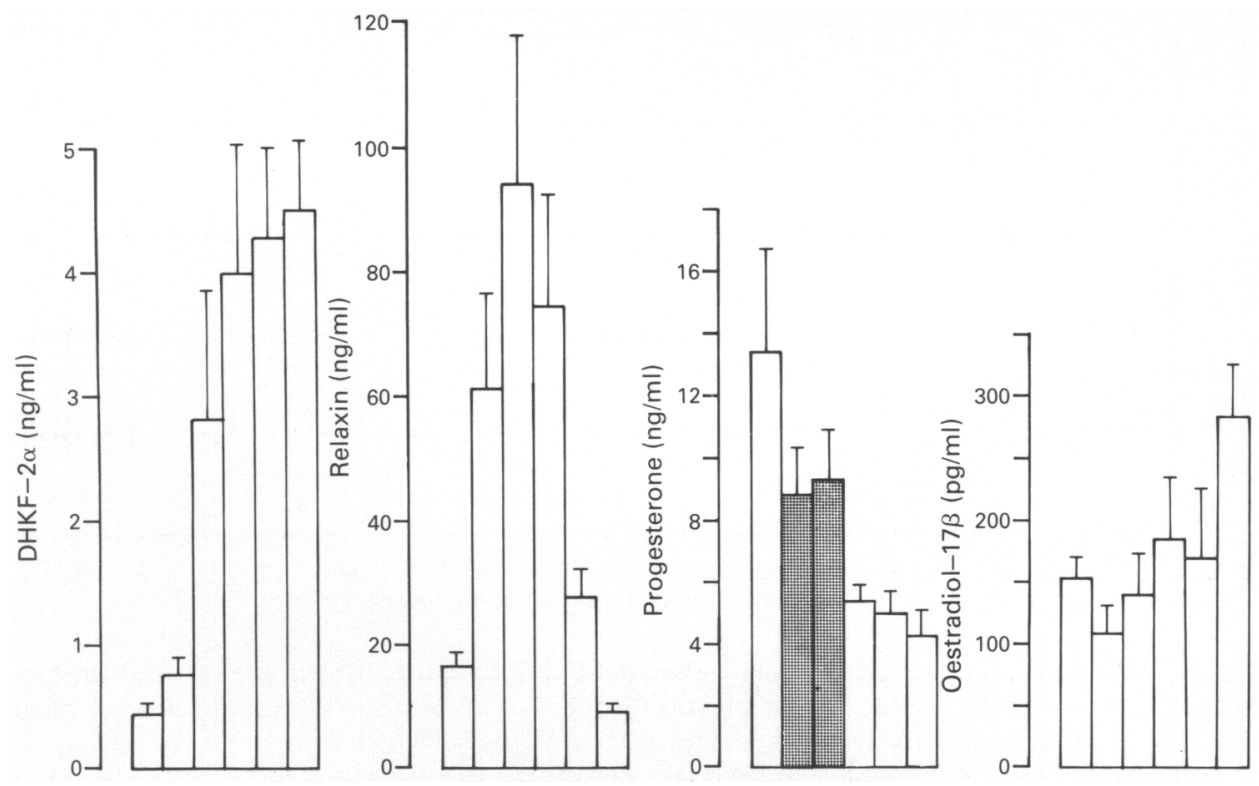

Fig. 4. Mean s.e. plasma concentrations of dihydro-keto-prostaglandin F-2 $\alpha$ (DHKF-2 $\alpha$ ), relaxin, progesterone and oestradiol-17 $\beta$ in each of $6 \times 5 \mathrm{~h}$ periods before birth in Group 1 (control) gilts. A difference in shading between adjacent columns indicates a significant difference between them $(P<0.05)$.

Table 1. Levels of probability of correlations between pairs of measurements in (a) each of 4 control gilts and (b) during the time intervals $\mathrm{A}-\mathrm{F}$ for all control gilts

\begin{tabular}{|c|c|c|c|c|c|c|c|}
\hline & & & & \multicolumn{4}{|c|}{ Gilts } \\
\hline \multicolumn{4}{|c|}{ Correlations } & 1 & 2 & 3 & 4 \\
\hline \multirow[t]{13}{*}{ (a) } & MTDEA & $v s$ & DHKF- $2 \alpha$ & $P<0.001$ & $P<0.001$ & $P<0.025$ & NS \\
\hline & MTDEA & vs & relaxin & $P<0.01$ & $P<0.001$ & $P<0.001$ & $P<0.01$ \\
\hline & MTDEA & $v s$ & progesterone & NS & NS & NS & NS \\
\hline & MTDEA & vs & oestradiol- $17 \beta$ & $P<0.05$ & NS & $P<0.05$ & $P<0.05$ \\
\hline & DHKF-2 $\alpha$ & $v s$ & relaxin & $P<0.05$ & $P<0.001$ & NS & $P<0.025$ \\
\hline & DHKF-2 $\alpha$ & $v s$ & oestradiol-17 $\beta$ & NS & NS & $P<0.05$ & NS \\
\hline & DHKF $2 \alpha$ & vs & progesterone & $P<0.001$ & $P<0.05$ & NS & NS \\
\hline & Progesterone & $v s$ & oestradiol-17 $\beta$ & NS & NS & NS & NS \\
\hline & Progesterone & vs & relaxin & NS & NS & NS & NS \\
\hline & Relaxin & vs & oestradiol-17及 & $P<0.05$ & NS & $P<0.05$ & NS \\
\hline & MTDEA & $v s$ & oestradiol-17ß/ & & & & \\
\hline & & & progesterone ratio & NS & $P<0.05$ & $P<0.01$ & $P<0.05$ \\
\hline & DHKF- $2 \alpha$ & $v s$ & $\begin{array}{l}\text { oestradiol-17ß/ } \\
\text { progesterone ratio }\end{array}$ & $P<0.05$ & $P<0.05$ & $P<0.05$ & $P<0.01$ \\
\hline \multirow{3}{*}{ (b) } & MTDEA & $v s$ & DHKF-2 $\alpha$ & $P<0.05$ & & & \\
\hline & MTDEA & & oestradiol-17 $\beta$ & $P<0.05$ & & & \\
\hline & DHKF- $2 \alpha$ & vs & progesterone & $P<0.05$ & & & \\
\hline
\end{tabular}

MTDEA = mean total duration of electrical activity; DHKF- $2 \alpha=$ dihydro-keto-prostaglandin F- $2 \alpha$; NS = not significant. 


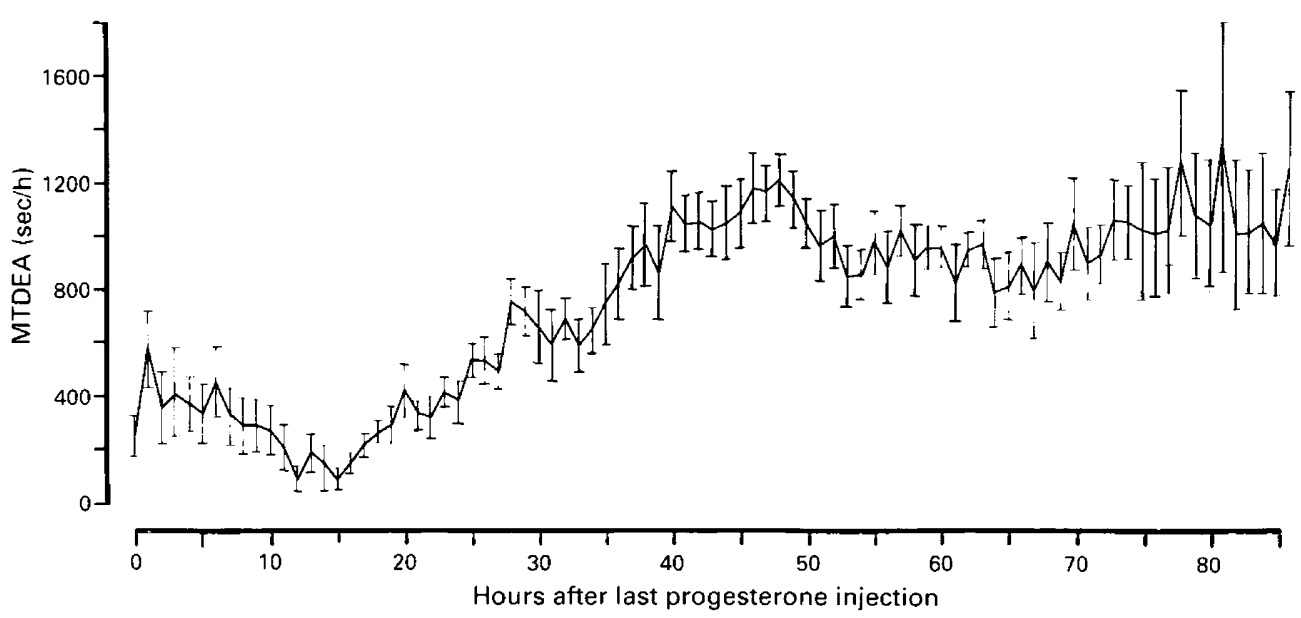

Fig. 5. Mean total duration of electrical activity (MTDEA) values for the period after the last progesterone injection (i.e. at $0 \mathrm{~h}$ ) in pigs in Group 2. The mean \pm s.e.m. values have been calculated from data obtained from 4 gilts up to $65 \mathrm{~h}, 3$ gilts from $65 \mathrm{~h}$ to $76 \mathrm{~h}$, from 2 gilts up to $81 \mathrm{~h}$ and from one to $90 \mathrm{~h}$. Continuous recordings were made from a total of 11 electrodes up to $55 \mathrm{~h}$, and not less than 5 electrodes from 55 to $81 \mathrm{~h}$.

gestation was prolonged compared to controls at $115.9 \pm 0.9$ days $(P<0.001)$. Although the gilts showed no overt signs of distress at this stage it was decided to attempt induction of delivery (4 animals) or to kill the animals humanely with an overdose of barbiturate administered intravenously.

Oxytocin infusion ( $650 \mathrm{mu} / \mathrm{ml}$ saline: Syntocinon, Sandoz Products Ltd, London, U.K.) at the rate of $112 \mathrm{mu} / \mathrm{min}(1$ gilt $)$ or relaxin $(400-500 \mu \mathrm{g} / \mathrm{h})$ infusion followed by oxytocin $(112 \mathrm{mu} / \mathrm{min})$ infusion ( 3 gilts) resulted in the overall delivery of only $54 \%$ of the piglets, although 2 gilts expelled their entire litters. All piglets delivered were still-born, and their mean weight was $355.7 \pm 15 \mathrm{~g}$. This was significantly less $(P<0.001)$ than the weight of live-born piglets in the control group, although significantly greater than the weight of still-born piglets in that group $(P<0.025)$.

Uterine EMG. Of 12 electrodes implanted in this group 11 functioned successfully up to $55 \mathrm{~h}$ after the last progesterone injection, after which further electrodes failed to transmit.

EMG activity varied among the gilts in Group 2 but did not appear to be influenced by the dose of progesterone administered. Three gilts exhibited erratic bursts of action potentials which were not fully co-ordinated. One gilt had regular high amplitude bursts of electrical activity which were co-ordinated among the three electrodes. This latter animal exhibited this type of activity from the time of surgery, showing an evolution of both frequency and amplitude which was unaffected by increasing doses of progesterone up to $2 \mathrm{mg} / \mathrm{kg}$.

Although EMG activity was not clearly affected by individual progesterone treatments, mean total duration of electrical activity showed a steady increase from a time some $11-15 \mathrm{~h}$ after the last progesterone injection, reaching a maximum level of $1162 \pm 50 \mathrm{sec} / \mathrm{h}$ at $46-50 \mathrm{~h}$ after treatment, comparable to levels found in control animals at the time of fetal expulsion. After this there was a significant reduction in activity $(P<0.05)$ with mean levels remaining stable at around $900 \mathrm{sec} / \mathrm{h}$ (Fig. 5).

Mean burst duration, mean maximum amplitude and mean frequency of electrical bursts changes were similar in character to those of mean total duration of electrical activity, although mean maximum amplitude did not show a decrease immediately after the last progesterone injection. Once again, the possibility of unknown impedence changes should not be disregarded when changes in mean amplitude are considered. 
Intrauterine pressure activity. All gilts showed low levels of IUP activity up to some $39-45 \mathrm{~h}$ after the last progesterone injection when IUP cycles began to develop. As with control gilts IUP cycles only developed after the increase in EMG activity had begun. The recordings of IUP in this group revealed only small, if any, rapid 'abdominal' pressure changes superimposed on the IUP cycles in contrast with recordings in the control gilts.

$D H K F-2 a$. Blood samples were obtained from 4 of the animals; of these, 3 exhibited peak plasma titres of between 6 and $14 \mathrm{ng} / \mathrm{ml}$ during the period $30-50 \mathrm{~h}$ after the last progesterone injection while the fourth had levels which fluctuated up to about $4 \mathrm{ng} / \mathrm{ml}$ from an erratic baseline of between 1 and $2 \mathrm{ng} / \mathrm{ml}$.

Relaxin. Relaxin was not detectable in any of the gilts during the post-operative period.

Progesterone. During the period of administration the mean plasma titres in gilts receiving $0.5 \mathrm{mg} / \mathrm{kg} /$ day was $13.7 \pm 1.6 \mathrm{ng} / \mathrm{ml}$, in those receiving $0.75 \mathrm{mg} / \mathrm{kg} /$ day it was $17.9 \pm 1.9 \mathrm{ng} / \mathrm{ml}$ and in those receiving $2.0 \mathrm{mg} / \mathrm{kg} /$ day it was $72.4 \pm 4.8 \mathrm{ng} / \mathrm{ml}$. All gilts showed a decline in plasma progesterone concentrations after the last progesterone injection to titres of $<10 \mathrm{ng} / \mathrm{ml}$ at the end of the experiment.

Oestradiol-17 $\beta$. With the exception of an unexplained surge in oestradiol- $17 \beta$ titres to $310 \mathrm{pg} / \mathrm{ml}$ between 30 and $60 \mathrm{~h}$ after the last progesterone injection in one gilt, all animals had titres of $<200 \mathrm{pg} / \mathrm{ml}$ which tended to decline steadily with time.

\section{Group 3: ovariectomized gilts treated with progesterone and relaxin}

Behaviour and gestational data. The behaviour of the gilts did not differ from that in Group 2 gilts even when time periods during the infusion of relaxin were compared with corresponding time periods of Group 2 gilts. None of the gilts in this group gave birth to their litters unaided even though gestation had been prolonged to $115.7 \pm 0.2$ days $(P<0.001)$ by the time induction was attempted. Each of the gilts in this group received an intravenous oxytocin infusion $(112 \mathrm{mu} / \mathrm{min})$ for $2 \mathrm{~h}$ : 2 gilts failed to expel any fetuses while 1 delivered 4 dead piglets $24 \mathrm{~h}$ after the infusion. Mean piglet weight was $267.5 \pm 29.6 \mathrm{~g}$ which was significantly lower $(P<0.001)$ than the weight of live born, but not different from weight of still-born, piglets in Group 1 .

Uterine EMG. All 9 electrodes implanted transmitted potentials from animals in Group 3 except for one electrode which failed from 19:00 h on Day 111 to 09:00 h on Day 113 of pregnancy.

As with Group 2, EMG activity bore no obvious relationship to the dose of progesterone given to the gilts and within limits of variation was comparable to that recorded from gilts in Group 2. However, EMG activity decreased markedly as soon as relaxin treatments were started (Fig. 6) and for a period the recordings showed virtual electrical quiescence. Nevertheless, as shown by mean total duration of electrical activity measurements, electrical activity gradually recovered despite continued relaxin administration (Fig. 6), reaching peaks of around 500, 1000 and $1200 \mathrm{sec} / \mathrm{h}$ in the 3 animals respectively at $70 \mathrm{~h}$ after the beginning of relaxin treatment.

Intrauterine pressure. IUP recordings were similar to those of Group 2 until relaxin treatments began when IUP cycles were abolished initially. There was a gradual resurgence of pressure cycles beginning shortly after the resumption of EMG activity.

$D H K F-2 a$. DHKF-2 $\alpha$ titres varied considerably in this group, showing a steady increase in one animal to $6.0 \mathrm{ng} / \mathrm{ml}$ at $14 \mathrm{~h}$ after the last progesterone injection followed by a decline, a series of peaks of $\sim 9.0 \mathrm{ng} / \mathrm{ml}$ in another followed by a decline, and no distinct rise in the third animal.

Relaxin. Relaxin was undetectable in samples taken before the purified hormone was administered.

In the 2 gilts in which relaxin was infused intra-arterially plasma titres were maintained throughout the infusion at $5 \cdot 2 \pm 0 \cdot 3$ and $9 \cdot 0 \pm 0 \cdot 2 \mathrm{ng} / \mathrm{ml}$ respectively. When the infusion was stopped plasma levels declined rapidly and were undetectable by $12 \mathrm{~h}$. In the gilt given intramuscular relaxin, plasma titres fluctuated rapidly with peak levels occurring about $1 \mathrm{~h}$ after each injection. Mean titres between 4.7 and $6.3 \mathrm{ng} / \mathrm{ml}$ with peaks up to $18.6 \mathrm{ng} / \mathrm{ml}$ were produced. 


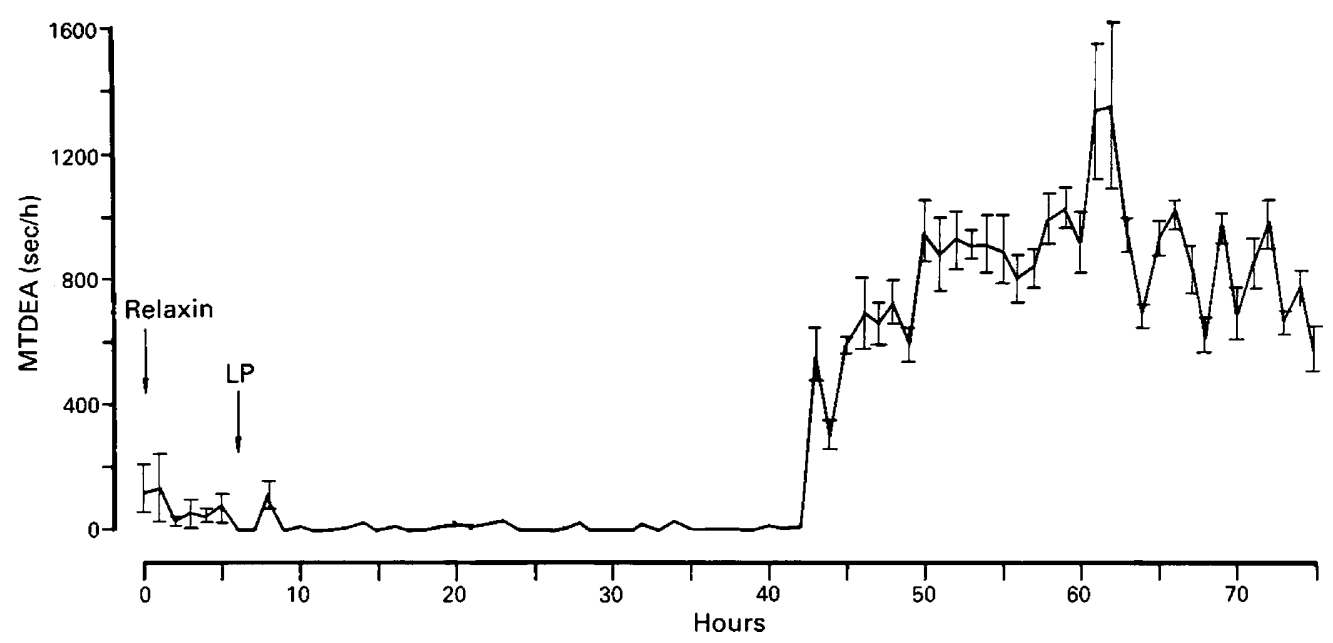

Fig. 6. Mean total duration of electrical activity (MTDEA) values of 1 gilt from Group 3 from the time that infusion of relaxin into the uterine artery was begun until the end of the experiment. LP $=$ last progesterone injection. Values are the means \pm s.e.m. of electrical activity recorded from 3 electrodes.

Progesterone. Plasma titres fluctuated between 20 and $160 \mathrm{ng} / \mathrm{ml}$ within and among the gilts but all 3 exhibited progressive falls during the $80 \mathrm{~h}$ of sampling after the last injection.

Oestradiol-17 $\beta$. In all 3 gilts plasma titres were above $100 \mathrm{pg} / \mathrm{ml}$ during most of the period of progesterone treatment, but fell between 1 and 5 days before the last injection. Titres were maintained between 20 and $40 \mathrm{pg} / \mathrm{ml}$ until the experiment was terminated.

\section{Discussion}

The gestational statistics and the behavioural activity of the control gilts were within the normal range (Jones, 1966a, b; Randall, 1972; Naaktgeboren, 1979), even though the animals were equipped with myometrial electrodes and intrauterine balloons. Recordings from these animals revealed that the myometrium is virtually inactive in late gestation up to a time some 12 to $5 \mathrm{~h}$ before the delivery of the first piglet, notwithstanding a sharp fall in plasma progesterone titres which occurred over the period from $30 \mathrm{~h}$ to term. Indeed no correlation could be detected between plasma progesterone concentration and the extent of electrical or mechanical activity in the myometrium. Since progesterone has been shown to be a potent inhibitor of myometrial activity in the pig (Porter \& Watts, 1985), the explanation for this apparent paradox may lie in the sequence of events, discernible from our data, which culminates in delivery.

The first change detected that presaged the onset of delivery was a decline in progesterone titres, which began at about $30 \mathrm{~h}$ pre partum and progressed to term. At about $20 \mathrm{~h}$ before delivery, plasma DHKF-2 $\alpha$ increased sharply, rising more slowly thereafter. The lack of any marked change in this metabolite concentration before this time argues against the view that PGF- $2 \alpha$ in the systemic circulation is responsible for initiating luteolysis in the pregnant sow. Similar conclusions were drawn from a less detailed analysis by Silver et al. (1979) although neither their study nor ours precludes the involvement of locally delivered PGF-2 $\alpha$ in the process of luteal regression.

In control gilts total EMG activity (Fig. 1) did not change between 20 and $10 \mathrm{~h}$ pre partum, despite a sharp increase in circulating DHKF-2 $\alpha$. However, in Group 2 gilts, which had been ovariectomized, EMG activity increased steadily from about $15 \mathrm{~h}$ after the last progesterone 
injection when plasma progesterone titres were falling below $40 \mathrm{ng} / \mathrm{ml}$. One explanation for this difference might be the sharp increase in plasma relaxin titres which occurred in control animals as progesterone concentrations waned. The profile of relaxin in our gilts was in agreement with that reported by others for normal sows (Sherwood et al., 1975, 1981; Kendall et al., 1982; Nara et al., 1982a; Taverne et al., 1982). Relaxin has been shown to be a myometrial inhibitor in vivo in the pig (Porter \& Watts, 1985) and the progressive rise in EMG activity observed in Group 2 gilts following the last progesterone injection was virtually abolished in Group 3 animals by the administration of relaxin. Relaxin appears therefore to maintain myometrial quiescence as the progesterone 'block' (Csapo, 1956; Porter \& Watts, 1985) wanes. When relaxin titres fell EMG activity increased progressively up to birth, as reflected by the significant negative correlation between relaxin and mean total duration of electrical activity. The evolution of EMG activity is accompanied by increasing mechanical activity after a delay.

It is clear, however, that myometrial activity is not inhibited indefinitely by relaxin because EMG bursts reappeared in Group 3 gilts despite continued infusion of the peptide. This is consistent with recent findings in rats (Jones \& Summerlee, 1986) that when parturition is postponed by relaxin infusion, some animals deliver their litters before the administration is stopped.

In control animals DHKF-2 $\alpha$ was positively correlated with EMG activity. However, there was a lag between the rises in DHKF-2 $\alpha$ and in EMG, which could be accounted for by the high circulating level of relaxin at this time. EMG activity increased most markedly when relaxin concentrations fell between 15 and $5 \mathrm{~h}$ pre partum. Indeed, EMG was suppressed in Group 3 animals for a period of $30-40 \mathrm{~h}$ by treatment with relaxin despite high levels of DHKF-2 $\alpha$ in 2 of the gilts. This contrasts with animals in Group 2, which were treated similarly except that no relaxin was given. In these gilts EMG activity increased in parallel with DHKF-2 $\alpha$ titres during the period from about 12 to $50 \mathrm{~h}$ after the last injection of progesterone. These results suggest that relaxin inhibits the myometrium while progesterone titres are falling and while circulating levels of PGF- $2 \alpha$ are increasing. Support for this conclusion comes from the finding that relaxin was able to inhibit PGF-2 $\alpha$-driven intrauterine pressure cycles in oestrogen-treated rats (Porter et al., 1979).

We were unable to induce normal deliveries in ovariectomized gilts maintained on progesterone by the administration of relaxin, thus failing to confirm the work of Nara et al. (1982b). However, our findings are not necessarily contradictory to the hypothesis that relaxin is essential for normal delivery in the pig. Due to the limits of our stock of the peptide none of the regimens of relaxin administration which we adopted reproduced the normal plasma profile of that hormone. Indeed, for most of the period after ovariectomy when progesterone was administered no relaxin was given, raising the possibility that the basal level of relaxin, which is sustained during late pregnancy, before the pre-partum spike, may be important in the preparation for birth. In our protocol a period of over 12 days elapsed between ovariectomy and the start of relaxin treatment. This may have been a crucial omission but the significance of relaxin secretion during this interval was probably not attributable to its effects on the cervix since this was quite soft, even though the animals failed to deliver their litters.

One feature demonstrated by our study is that it is difficult to interpret myometrial activity satisfactorily from EMG records alone since it was clear that the development of significant mechanical activity often followed the emergence of electrical activity by an interval of $2-3 \mathrm{~h}$. It is therefore possible to have considerable electrical activity without accompanying mechanical force development.

We thank Mr Roger Jones and Mrs Jackie Rees for expert technical assistance; Ms C. de la Mahotiere for writing the computer analysis program; Mr S. Kelly and Dr D. Kelly for help with the statistical analysis; Dr P. Piraino for her skills as an anaesthetist; Dr W. A. Kelly for helpful criticism of the manuscript; Mrs A. Moody for typing the manuscript; and the AFRC and MRC for financial support. 


\section{References}

Csapo, A.I. (1956) Progesterone block. Am. J. Anat. 98, 273-291.

Foxcroft, R., Elsaesser, F., Stickney, K., Haynes, N.B. \& Back, H.L. (1984) Ovarian oestrogen-dependent maturation of the $\mathrm{LH} / \mathrm{FSH}$ urge mechanism during prepubertal development in the gilt. $J$. Endocr. 101, 371-380.

Haresign, W., Foster, J.P., Haynes, N.B., Crighton, D.B. \& Lamming, G.E. (1975) Progesterone levels following treatment of seasonally anoestrous ewes with synthetic LH-releasing hormone. J. Reprod. Fert. 43, 269-279.

Jones, J.E.T. (1966a) Observations on parturition in the sow. Part 1: The pre-partum phase. Br. vet. J. 122, $420-426$.

Jones, J.E.T. (1966b) Observations on parturition in the sow. Part II: The parturient and post-parturient phases. Br. vet. J. 122, 471-478.

Jones, S.A. \& Summerlee, A.J.S. (1986) Effects of porcine relaxin on the length of gestation and duration of parturition in the rat. $J$. Endocr. 109, 8588 .

Kendall, J.Z., Richards, G.E., Shih Li-Chen, N. \& Farbis, T.S. (1982) Plasma relaxin concentrations in the pig during periparturient period, association with prolactin, oestrogen and progesterone concentrations. Theriogenology 17, 677-687.

Mitchell, M.D., Flint, A.P.F. \& Turnbull, A.C. (1975) Stimulation by oxytocin of prostaglandin $F$ levels in uterine venous effluent in pregnant and puerperal sheep. Prostaglandins 9, 47-56.

Naaktgeboren, C. (1979) Behavioural aspects of parturition. Anim. Reprod. Sci. 2, 155-166.

Nara, B.S., Ball, G.D., Rutherford, J.E., Sherwood, O.D. \& First, N.L. (1982a) Release of relaxin by a nonluteolytic dose of prostaglandin $F_{2 a}$ in pregnant swine. Biol. Reprod. 27, 1190-1195.

Nara, B.S., Welk, F.A., Rutherford, J.E., Sherwood, O.D. \& First, N.L. (1982b) Effect of relaxin on parturition and frequency of live births in pigs. $J$. Reprod. Fert. 66, 359-365.

Porter, D.G., Downing, S.J. \& Bradshaw, J.M.C. (1979) Relaxin inhibits spontaneous and prostaglandin driven myometrial activity in anaesthetized rats. $J$. Endocr. 83, 183-192.

Porter, D.G., Lye, S.J., Bradshaw, J.M.C. \& Kendall, J.Z. (1981) Relaxin inhibits myometrial activity in the ovariectomized non-pregnant ewe. $J$. Reprod. Fert. 61, 409-414.

Porter, D.G. \& Watts, A.D.(1985) Relaxin and progesterone are myometrial inhibitors in the ovariecto- mized non-pregnant mini-pig. J. Reprod. Fert. 76, $205-213$.

Randall, G.C.B. (1972) Observations on parturition in the sow. I. Associated factors with the delivery of the piglets and their subsequent behaviour. II Factors affecting stillbirths and perinatal mortality. Vet. Rec. 90, 178-182.

Sherwood, O.D., Chang, C.C., Bevier, G.W. \& Dziuk, P.J. (1975) Radioimmunoassay of plasma relaxin levels throughout pregnancy and at parturition in the pig. Endocrinology $97,834-837$.

Sherwood, O.D., Nara, B.S., Welk, F.A., First, N.L. \& Rutherford, J.E. (1981) Relaxin levels in the maternal plasma of pigs before, during and after parturition and before, during and after suckling. Biol. Reprod. $25,65-71$.

Siegal, S. (1956) Non-parametric Statistics for the Behavioral Sciences. McGraw-Hill, New York.

Silver, M., Barnes, R.J., Comline, R.S., Fowden, A.L., Clover, L. \& Mitchell, M.D. (1979) Prostaglandins in the fetal pig and pre-partum endocrine changes in mother and fetus. Anim. Reprod. Sci. 2, 305-322.

Taverne, M.A.M. (1982) Myometrial activity during pregnancy and parturition in the pig. In Control of Pig Reproduction, pp. 419-436. Eds D. J. A. Cole \& G. R. Foxcroft. Butterworth Scientific, London.

Taverne, M.A.M., Naaktgeboren, C., Elsaesser, F., Forsling, M.L., Van Der Weyden, G.C., Ellendorf, F. \& Smidt, D. (1979a) Myometrial electrical activity and plasma concentrations of progesterone, oestrogen and oxytocin during late pregnancy and parturition in the miniature pig. Biol. Reprod. 21, 1125-1134.

Taverne, M.A.M., Naaktgeboren, C. \& Van Der Weyden, G.C. (1979b) Myometrial activity and expulsion of fetuses. Anim. Reprod. Sci. 2, 117-131.

Taverne, M.A.M., Beviers, M., Bradshaw, S.J., Dieleman, S., Willemse, A.H. \& Porter, D.G. (1982) Plasma concentrations of prolactin, progesterone, relaxin and oestradiol-17 $\beta$ in sows treated with progesterone, bromocriptine or indomethacin during late pregnancy. J. Reprod. Fert. 65, 85-96.

Wathes, D.C. \& Porter, D.G. (1982) Effect of uterine distension and oestrogen treatment on gap junction formation in the myometrium of the rat. $J$. Reprod. Fert. 65, 497-505.

Zerobin, K. \& Sporri, H. (1972) Motility of the bovine and porcine uterus and fallopian tube. Adv. vet. Sci. comp. Med. 16, 303-354.

Received 11 August 1987 